\title{
A saúde pública entre a Medicina e a Política: as propostas de Ribeiro Sanches no Portugal das Luzes*
}

Public health of Medicine and Politics: proposals for Ribeiro Sanches in Enlightenment's

Portugal

\author{
Julie Hamacher Liepkaln \\ Mestranda em História \\ pela Universidade Estadual de Campinas \\ juhamacher@gmail.com
}

\begin{abstract}
Resumo: Partindo da análise da produção intelectual do médico português Antônio Nunes Ribeiro Sanches, investigaremos como suas propostas reformistas destinadas à conservação da saúde da população portuguesa foram apropriadas e engendraram políticas de saúde pública, muitas delas aplicadas pela Intendência Geral da Polícia. Para tanto, perscrutaremos o cenário ilustrado na segunda metade do Setecentos - contexto de produção das obras de Sanches -, atentando-nos aos debates acerca das potenciais utilidades do conhecimento científico. Ao relacionarmos as propostas de Sanches com os esforços de normatização e controle da atividade médica, pretendemos compreender como a salvaguarda da saúde pública conjugava questões de ordem científica - a consolidação do saber médico enquanto ciência - e de ordem política - o fortalecimento do poderio da monarquia portuguesa.
\end{abstract}

Palavras-chave: Ilustração; Medicina; Antônio Nunes Ribeiro Sanches.

\begin{abstract}
Based on the analysis of the Portuguese physician Antônio Nunes Ribeiro Sanches' intellectual production, this article seeks to investigate how his reformist proposals for the Portuguese population health preservation were appropriate and engendered public health policies, many of them implemented by the Intendência Geral da Polícia. For this purpose, it is necessary to inquire into the Enlightenment movement in eighteenth century's second half - context of Sanches' works - paying attention to the debates about the potential uses of scientific knowledge. Therefore we aim to understand how public health conjugated scientific issues - the consolidation of medical knowledge as a science - and political issues - the strengthening of Portuguese monarchy's power.
\end{abstract}

Keywords: Enlightenment; Medicine; Antônio Nunes Ribeiro Sanches.

\footnotetext{
* Fonte Financiadora: FAPESP.
} 
O século XVIII constituiu um momento paradigmático na história da ciência de uma forma geral e, mais especificamente, na história da medicina. Ao longo do chamado século das Luzes, intensificou-se o debate em torno das ideias de liberdade, progresso e razão entre indivíduos de variadas ocupações e localidades do continente europeu. Além de refletirem sobre sua própria realidade, muitos pensaram em como transformá-la, valendo-se do conhecimento e da ciência, os quais não se resumiam a meras contemplações e formulações de hipóteses, mas eram concebidos como instrumentos de intervenção nas estruturas políticas e sociais vigentes. Assim, no caso da saúde pública, o imperativo de um "bem-estar" coletivo tornar-se-ia viável através da intervenção do Estado, o qual aliado, à ciência médica, seria capaz de garantir melhores condições de vida para a população.

Diante deste cenário, pretendemos abordar no presente artigo a articulação entre o discurso médico ilustrado e o poder político na segunda metade do Setecentos em Portugal. Para tanto, gostaríamos de nos deter sobre a atuação do médico português Antônio Nunes Ribeiro Sanches (1699 - 1783). Devido a sua origem judaica, em 1726 Sanches deixou Portugal com destino a Londres. Desde então, o médico passou por diversas cidades europeias, algumas nas quais fixou residência por alguns anos, como Montpellier, Leiden, São Petersburgo e Paris. Ao longo de suas viagens, Sanches, além de frequentar diferentes universidades, academias e sociedades científicas europeias, acabou por consolidar uma importante rede de contatos. Tanto a amplitude de sua rede de contatos, bem como as atividades desenvolvidas pelo médico luso nas academias às quais se filiou - ora como membro oficial, ora como correspondente -, conferiram-lhe prestígio perante cientistas e indivíduos direta ou indiretamente implicados no exercício da política portuguesa (DULAC, 2002) .

Apesar de Sanches, enquanto cristão-novo, ter deixado Portugal sem nunca mais voltar, o exílio, contudo, não o impediu de refletir e alvitrar soluções aos problemas de seu país natal, como por exemplo, a estrutura do ensino básico e superior ou as atividades da Inquisição. Justamente por conta de seu prestígio, acreditamos que determinadas propostas suas, ao circularem tanto em espaços científicos, quanto políticos, reverberaram na sociedade portuguesa. Portanto, mais do que analisarmos a produção intelectual de Ribeiro Sanches, pretendemos também verificar como tal produção deu ensejo à formulação das políticas destinadas à saúde pública. Tal esforço consiste em articular as esferas científica - sobretudo, as redes e espaços de 
sociabilidade e a consolidação da ciência médica - e política - o exercício do poder e o estabelecimento de políticas públicas.

Retornemos ao século das Luzes. Quanto aos debates desenvolvidos entre os philosophes, evidentemente que estes possuíam suas discordâncias, sendo que até a própria noção de progresso foi questionada por Rousseau. Defensor da tese da perfectibilidade, Rousseau acreditava que a despeito da existência de um dispositivo de progresso na humanidade, o mesmo não era garantido. Todavia, não podemos deixar de notar também certa concordância no que se refere ao valor do conhecimento e da ciência. Neste sentido, o texto Resposta à pergunta: "Que é Esclarecimento?”, escrito por Kant, mostra-se emblemático. Nele, Kant ressalta a magnitude do uso público que cada indivíduo pode fazer de sua própria razão sem a ajuda ou tutela de alguém. Tal gesto, qual seja, o de ousar saber - sapere aude -, possibilitaria ao homem a saída da menoridade, forma de se livrar de qualquer tipo de dominação, adquirindo-se assim a liberdade (KANT, 1974).

Contemporâneos de Kant, cientistas ilustrados entregaram-se à missão de "publicizar a razão" e de transmitir saberes "legítimos", com o propósito de prevenir determinados prejuízos à população. Para estes homens, o saber, outrora "hermético", deveria ser compartilhado e ter acesso mais amplo. Neste sentido, as sociedades científicas e as grandes academias, espaços destinados à "construção do conhecimento" e a formas de sociabilidade e legitimação social científica, foram ambientes intelectuais cooperativos paradigmáticos.

O esforço de publicização da razão, acompanhado de certo pedagogismo, manifestou-se no enciclopedismo - que englobava não somente a célebre Encyclopédie de Diderot e d'Alembert, como também jornais científicos, que buscavam difundir novos experimentos e técnicas -, movimento que se prestou à compilação e divulgação de todo o conhecimento até então produzido pela humanidade. No caso de Portugal, entre 1715 a 1807, dentre os 84 periódicos fundados no período, cerca de $40 \%$ tinham caráter enciclopédico, o que revela a disseminação do movimento enciclopedista para além daquele que foi considerado seu epicentro, a cidade de Paris. Cabe destacar o Jornal Enciclopédico dedicado à Rainha N. Senhora, que foi um importante veículo de divulgação científica e igualmente um suporte da opinião pública ilustrada.

No caso da medicina, mais especificamente, também vale citar os manuais domésticos de saúde, cujo objetivo, para além de educar a população em termos de higiene, era o de normatizar certas práticas, "condenando-se" assim o trabalho de 
“charlatães" e profissionais não licenciados. Consideravelmente populares foram os tratados escritos por William Buchan (1729 - 1805) e Samuel Auguste Tissot (1728 1797), autores que, embora almejassem um público o mais amplo possível, estavam cientes da principal limitação ao alcance de suas obras: a maioria dos leitores provinha de camadas populares e, portanto, não sabia ler. No entanto, Buchan e Tissot também pressupunham que, em última instância, seus ensinamentos poderiam ser aprendidos pela via auditiva, uma vez que fossem lidos em voz alta (MARQUES, 2003: 3).

Podemos constatar, diante disso, que a atuação dos cientistas ilustrados certamente voltou-se para a ação e para a preocupação com o bem comum. Porém, se por um lado estes cientistas valeram-se da práxis e da léxis para discutir e incentivar o amplo uso do conhecimento e da ciência como instrumentos de intervenção nas estruturas políticas e sociais vigentes, por outro, sua atuação também foi permeada por interesses particulares. Como os manuais domésticos de saúde bem exemplificam, havia neste período toda uma preocupação em se distinguir os profissionais de saúde "oficiais" - essencialmente, médicos, boticários e cirurgiões -, dos agentes que compunham a esfera da medicina popular - parteiras, curandeiros, sangradores e empíricos. Conforme Mary Lindemann aponta, “(...) a sobreposição das medicinas "popular" e "elitista" representava um largo substrato de crenças comuns sobre a saúde, a doença e as terapêuticas, que a maior parte da sociedade partilhava, e que caracterizava justamente a medicina na Idade Moderna.” (LINDEMANN, 2002: 12). Se havia uma diferenciação entre estes dois grupos, esta se justificava menos por questões de conhecimento e mais por aspectos de distinção social (LEBRUN, 1995: 35).

$\mathrm{O}$ fato de os médicos licenciados adotarem diversos métodos empregados por curandeiros e práticos colocava em cheque a sua legitimidade. Além disso, não se poupavam críticas ao modelo de ensino da medicina vigente no continente europeu, o qual se baseava fundamentalmente nas teorias de Hipócrates e Galeno e possuía forte influência da filosofia escolástica. A preponderância do conhecimento teórico, em detrimento do prático, acarretou um padrão de ensino médico que prescindia de atividades práticas, como a anatomia. Esta última encontrava-se dissociada da medicina, tanto por motivos religiosos, quanto culturais. Além de proibida por ser concebida como um atentado à integridade do corpo humano, mesmo após a morte, a anatomia era claramente uma atividade manual $\mathrm{e}$, portanto, inferior às atividades ditas intelectuais.

Já no século XVII, tanto a prática, quanto o ensino médicos foram alvos de críticas. A obra $\mathrm{O}$ doente imaginário, escrita em 1673 pelo dramaturgo francês Molière 
(1622 - 1673), é uma comédia de costumes que satiriza os médicos seiscentistas, sobretudo suas linguagens e suas pretensões, como bem podemos observar no seguinte excerto: "Ils savent la plupart de fort belles humanités, savent parler em beau latin, savent nommer em grec toutes les maladies, les définir et les diviser; mais pour ce qui est de les guérir, c'est qu'il ne savent point de tout.” (MOLIÈRE; HUCHER, 1970: 13).

Tal excerto corresponde à fala de Béralde dirigida a seu irmão, Argan, personagem à qual o título faz referência. Béralde, indignado com a situação de Argan que, acreditando estar doente, abandona-se completamente aos cuidados de seus médicos -, busca convencer seu irmão da ineficácia do saber destes profissionais: eles não dominam de forma efetiva as artes de curar, porém, munidos de uma suposta erudição, tais médicos acabam por se beneficiar da credulidade de seus pacientes.

No século seguinte, mais especificamente em 1738, o escritor português Francisco Xavier de Oliveira (1702 - 1783), também conhecido como Cavaleiro de Oliveira, escrevera em uma carta à Condessa de N. a respeito dos médicos e boticários:

Ainda que com o socorro da anatomia se podem conhecer, como êle dizia, tôdas as diferentes partes do corpo humano e tôdas as suas diversas funções, como é possível que se conheça a origem de todas as enfermidades? (...) Se o médico não pode chegar a descobrir o particular do mal, como é que poderá aproveitar na aplicação do remédio? (OLIVEIRA; RAMOS, 1968: 60)

A crítica de Oliveira mira, sobretudo, a suposta exatidão do diagnóstico dos médicos, da qual estes próprios se gabam.Não obstante escreverem em momentos e locais distintos, tanto Molière, quanto Oliveira nos revelam, de maneira geral, elementos acerca da prática e saber médico. No que tange à prática médica, a expressão latina "Saignare, purgare et clysterium donare" resume os mais recorrentes procedimentos terapêuticos empregados pelos médicos eruditos . Através de sangrias, purgações e clísteres, os médicos estimulariam a secreção dos humores corrompidos, eliminando assim a causa da enfermidade. A esses procedimentos, podemos adicionar o uso de poções, unguentos e emplastros feitos à base de componentes de origem animal e, principalmente, vegetal. Também vale assinalar que, da colheita à preparação de tais medicamentos, seguia-se uma série de critérios, inclusive astrológicos e religiosos (GRMEK, 1995: 8). 
No Portugal do Setecentos, a situação não foi diferente. Segundo Timothy Walker, durante o reinado de D. João V (1707 - 1750), os médicos licenciados pela Universidade de Coimbra valiam-se tanto de métodos aprendidos no curso de medicina, quanto de rituais comumente realizados por curandeiros (WALKER, 2005: 117). Isto posto, o procedimento de considerar a apropriação de práticas populares por médicos acadêmicos, assim como o contrário, mostra-se fundamental à compreensão do discurso médico e das disputas em torno das artes de curar no século XVIII. Neste sentido, Tânia Pimenta, historiadora que analisou os documentos da Fisicatura-mor com o intuito de ponderar sobre a relação entre aquela instituição e os diferentes agentes de cura, nos coloca uma importante observação: "Mas a relação entre essas medicinas não acontecia apenas como imposição, por um lado, e resistência por outro. Alguns medicamentos preconizados pelos médicos acadêmicos podiam ser utilizados pelos praticantes da medicina popular e, certamente, o oposto também ocorria." (PIMENTA, 1997: 85 - 86).

Confrontados com este intercâmbio de práticas entre as esferas médicas erudita e popular, diversos letrados portugueses desaprovaram tal situação e buscaram combatêla por meio de formulações de medidas dirigidas ao ensino universitário e aos órgãos responsáveis pela regulamentação das atividades médicas. Autores como Luís Antônio Verney (1713 - 1792), Jacob de Castro Sarmento (1692 - 1762) e Antônio Nunes Ribeiro Sanches - devidamente já apresentado - alertaram sobre a escassez de médicos licenciados e, consequentemente, o predomínio de empíricos e outros tipos de profissionais sem formação nas atividades de assistência à saúde. Diante de tais circunstâncias, propuseram como soluções novas diretrizes para o ensino superior e igualmente novas políticas de regulamentação e fiscalização das atividades médicas e de seus agentes.

Conforme afirmado no início deste texto, gostaríamos de deter nossa atenção sobre Ribeiro Sanches e sua produção bibliográfica, cuja análise nos permite identificar um discurso médico que, embora pautado sobre diversos argumentos científicos, também é imbuído de todo um viés político. Mais do que intentar circunscrever e legitimar a atividade médica acadêmica, estabelecendo assim um monopólio da prática, Sanches entende a saúde pública como um projeto político, pois insiste em uma relação intrínseca entre o poder de um Estado e a saúde de seus súditos. No que tange tal relação, a introdução de sua obra Tratado da Conservação da Saúde dos Povos mostrase emblemática: 
Todos sabem que a mais sólida base de um poderoso Estado consiste na multidão dos súbditos, e no seu aumento, e que desta origem resultam as suas forças, poder grandeza e majestade (...). Mas como poderá aumentar-se sem leis, e regramentos a Conservação da Saúde dos Povos, e curar as enfermidades a que estão expostos? (SANCHES, 2003a: 3)

A ressonância dos escritos de Sanches pode ser observada, por exemplo, na reforma da Universidade de Coimbra, em 1772, para a qual contribuiu com o seu o Método para aprender e estudar a medicina. Com efeito, tal reforma é um claro exemplo de esforço de uma consolidação institucional e de uma reformulação das bases da ciência médica, adotando-se novos métodos e linguagens, entre eles, o iatromecanicismo - sistema de explicação dos fenômenos fisiológicos através de modelos mecânicos - e os estudos anatômicos (ABREU, 2007). Ainda sobre a reforma universitária de Coimbra, igualmente importante foram as edificações de três espaços para o aprendizado médico: o dispensatório farmacêutico, o teatro anatômico e o hospital escolar (PITA, 2000). Este último merece especial atenção. Para Michel Foucault, mais do que um local de formação de um saber específico, o hospital converte-se em um local de exercício de poder, onde observar, diagnosticar e corrigir tornam-se procedimentos exclusivos ao médico, profissional capaz de intervir sobre os indivíduos (FOUCAULT, 1998). Dialogando com o filósofo francês, o historiador Roy Porter complementa: “(...) quanto mais a profissão médica afirma sua capacidade de intervir sobre o corpo dos indivíduos, mais a sua ambição de também cuidar da sociedade como um todo também aumenta." (GRMEK, 1995: 223).

Tanto em o Tratado, quanto em o Método, é possível notar uma acentuada preocupação com a saúde pública, pois, para Sanches, um ensino médico bem fundamentado seria a condição básica para a manutenção da saúde da população. Em um mesmo diapasão, constatamos em seu texto Apontamentos para estabelecer-se um Tribunal e Colégio de medicina toda uma atenção ao "bem-estar" dos súditos. Nele, Sanches propõe a criação de um Tribunal e um Colégio de medicina, que seriam incumbidos principalmente de avaliar os agentes de saúde, distribuí-los pelas diversas regiões do país e recolher informações sobre as principais doenças e epidemias (SANCHES, 2003b).

Para Sanches, Tribunal e Colégio prestar-se-iam a substituir a Fisicatura-Mor, instituição criada em 1515 e que tinha a sua frente o Físico-mor, cargo normalmente 
ocupado pelo primeiro médico-régio, responsável pela fiscalização e concessão de licenças aos agentes de cura, os quais eram avaliados segundo seus conhecimentos teóricos e práticos. A Fisicatura-mor não foi considerada malograda apenas por Sanches. Antes disso, já em 1589, médicos diplomados pela Universidade de Coimbra reivindicavam a suspensão da autoridade do Físico-mor, alegando que este, mais preocupado com as contrapartidas financeiras do que com o exercício da medicina, concedia licenças a empíricos, alimentando assim o mercado paralelo e concorrencial dos médicos. A Coroa, dividida, buscava manter um equilíbrio, ora investindo no ensino médico, ora conferindo títulos e honrarias ao Físico-mor (ABREU, 2014: 39 - 161).

Assim, as propostas de Sanches tinham um claro escopo: em um primeiro momento, assinalar a autoridade da medicina acadêmica em detrimento da medicina popular e, em seguida, assegurar a salvaguarda da saúde da população portuguesa. Contudo, face ao esforço de combate à medicina paralela havia uma série de dificuldades, ambiguidades e tensões, não apenas entre profissionais licenciados e agentes populares de cura, mas também entre os próprios médicos.

Primeiramente, a realidade sanitária portuguesa na Idade Moderna configuravase como um verdadeiro obstáculo. Devido às más condições higiênicas, à alimentação deficiente e, especialmente, à ausência de médicos nas vilas mais isoladas, o trabalho de cura e alívio dos achaques era exercido por médicos empíricos, curandeiros e outros tipos de profissionais não licenciados. Mais tarde, à medida em que o ensino médicocirúrgico foi sendo organizado institucionalmente, todos estes profissionais passaram a ser referidos indiscriminadamente como "charlatães" pelos médicos acadêmicos, em uma estratégia clara de desprestigiar seus principais concorrentes nas artes de curar (PIMENTA, 1997: 44 - 80). Segundo Jorge Crespo, neste campo de disputas pelo monopólio da atividade médica, os médicos licenciados encontravam-se em uma posição bastante instável, uma vez que os próprios enfermos desconfiavam de seus métodos, que “(...) nada de novo acrescentavam ao que os curandeiros invariavelmente recomendavam.” (CRESPO, 1990: 118). Para além disso, devido à sua posição social os agentes da medicina popular tinham ao seu favor o fato de compartilharem o mesmo léxico da maioria da população.

Em segundo lugar, a despeito da reforma de Coimbra ter sido uma medida significativa para a organização institucional do ensino médico-cirúrgico, ela não foi capaz de consolidar a unificação das práticas médicas em Portugal. De fato, muitos médicos e cirurgiões lusos - e também de outros países europeus - tinham, além de 
Coimbra, a opção de estudarem em outras universidades, sendo as mais célebres as de Pisa, Bolonha, Paris, Montpellier, Leiden e Edimburgo. Além de cada curso de medicina fundamentar-se sobre um currículo específico, os médicos filiavam-se às correntes teóricas as mais diversas - por exemplo, o mecanicismo, o animismo e o vitalismo. Consequentemente, no discurso médico, distintas concepções de doença e saúde conviviam entre si, o que dificultava o estabelecimento de uma autoridade homogênea e coerente.

A título de exemplo, no supracitado Tratado da Conservação da Saúde dos Povos, Ribeiro Sanches pauta-se tanto em cientistas modernos, quanto em Hipócrates, unindo a teoria da irritabilidade das fibras musculares, de Albrecht von Haller, e a teoria hipocrática dos humores: "[A aguardente] Tomada na quantidade que determinamos fortifica todas as fibras do corpo e principalmente as do estômago, já relaxado nos tempos da calmaria e calor excessivo: embalsama os nossos humores." (SANCHES, 2003a: 74)

Se o médico português dialoga tanto com a ciência moderna, cujas premissas e métodos são assentados no racionalismo e no empirismo, quanto com as teses hipocráticas, isto não indica um abandono de crenças ou mesmo de explanações baseadas no divino. Sanches, por exemplo, discorrendo sobre a corrupção do ar e uma das maneiras de evitá-la através da utilização de arômatas, afirma que "somente entre os trópicos nascem os aromas e toda a sorte de especiarias: é admirável a providência do Altíssimo que naqueles lugares (...) se geram os mais fragantes aromas, e na maior abundância (...)" (SANCHES, 2003a: 14). No debate específico sobre a relação entre o ar e as enfermidades, Sanches adequa três diferentes perspectivas - a tradicional, a moderna e a religiosa.

Gesto imprescindível, identificar as divergências e a coexistência de diferentes teorias no discurso médico setecentista permite ao historiador "des-singularizar" a ciência médica, ou seja, romper com a visão desta como um bloco, que repousa sobre bases sólidas e estáveis. Aqui, cabe retomar a perspectiva epistemológica de Ludwik Fleck, autor que ressalta o dinamismo do processo de construção do conhecimento científico: "Le savoir ne repose sur aucun substrato; les idées et les verités n'existent que grâce à des mouvements et des interactions constants." (FLECK, 2005: 94) .

Para Fleck, posto que a doença, enquanto objeto de estudo, corresponde a um processo complexo, sobre o qual não há um entendimento unânime, o saber sobre ela, a medicina, constitui-se como um emaranhado de teorias e concepções, compartilhadas 
por diferentes grupos, que podem ser "esotérios" - indivíduos internos à esfera científica - ou "exotéricos" - neste caso, indivíduos externos. As ideias científicas não somente circulam por estes grupos, como também são reinterpretadas e "traduzidas" para outras linguagens.

Ainda, valendo-nos dos subsídios teóricos oferecidos pelos historiadores da ciência, não poderíamos deixar de citar o filósofo Thomas Kuhn e sua obra A estrutura das revoluções científicas. Nela, Kuhn logra realizar uma revisão dos critérios da historiografia da ciência através do conceito de "paradigma", definido como o conjunto de realizações científicas universalmente conhecidas que, durante algum tempo, fornecem problemas e soluções para uma comunidade de praticantes de uma ciência (KUHN, 2009: 13). Em um determinado campo científico, diante da crise nos métodos de resolução, os quais não são capazes de fornecer a explicação de alguma "anomalia", estabelece-se uma disputa por um novo paradigma. Assim, a teoria de Thomas Kuhn nos auxilia a elucidar as noções médicas presentes nos textos de Sanches, as quais encerram conceitos antigos e modernos dos sistemas humoral e mecanicista, respectivamente. Segundo o filósofo, quando um paradigma deixa de ser considerado válido, isto não significa que o novo paradigma prescindirá de elementos do anterior, incorporando, por exemplo, parte de seu vocabulário.

Em uma primeira leitura do discurso de Sanches, os conceitos e recursos analíticos da história da ciência revelam-se profícuos, pois nos possibilitam identificar os elementos dinâmicos da prática científica, como a circulação de ideias, as divergências e concordâncias em torno de concepções específicas e a disputa pela legitimidade de uma determinada ideia ou teoria. Entretanto, gostaríamos de considerar o discurso de Sanches - e mesmo o discurso de outros cientistas ilustrados - para além do âmbito científico.

Nesta perspectiva, a proposição do livro O Leviatã e a bomba a vácuo, qual seja, a de problematizar a cultura experimental inaugurada no século XVII, mostra-se bastante pertinente a presente reflexão. Para os autores, Shapin e Shaffer, o experimento, prática fundamental à construção do conhecimento moderno e ao estabelecimento de fatos, é, ao mesmo tempo, categoria epistemológica e social, posto que confere maior grau de probabilidade a certas hipóteses, como também só adquire sentido quando testemunhado e reproduzido por outros indivíduos. Detendo-nos neste aspecto social, o experimento não pode prescindir da coletividade, perante a qual o cientista se coloca e da qual ele busca o convencimento e a aprovação. 
Interessantemente, o discurso científico mobiliza esta ideia de coletividade, sublinhando-se a importância do trabalho coletivo e cooperativo em oposição ao individualismo ou hermetismo, mas também omitindo as rivalidades e discórdias que organizam as atividades científicas (SHAPIN; SCHAFFER, 1985).

Ademais, concordamos com a afirmação de Shapin e Shaffer de que a história da ciência ocupa o terreno da história política. Ora, primeiramente, a justificativa de um modo de produção de conhecimento é uma ação política, uma vez que implica negociações, disputas e persuasões. Em segundo lugar, o conhecimento científico estende-se à esfera política, pois ele repousa sobre regras específicas e instituições. Por fim, especialmente ao longo da Idade Moderna, conforme já afirmamos acima, os cientistas e letrados defrontaram-se com o debate sobre o caráter público da ciência.

Ao lermos a produção bibliográfica de Sanches podemos perceber como o "fazer" da ciência, a despeito de ser frequentemente associado a experimentos, técnicas e inventos - sobrepujando-se assim um enfoque sobre a prática -, também se expressa através de discursos e retórica. Isto posto, julgamos que, em uma segunda leitura dos documentos, a história das ideias e a história das linguagens políticas nos proporcionam uma diferente perspectiva analítica do campo científico.

Autores como Quentin Skinner e John Pocock realizam críticas concisas ao pósestruturalismo, corrente teórica que admite a linguagem como um sistema auto referencial, capaz de constituir seus próprios significados em detrimento do autor - cuja "morte" foi anunciada por Roland Barthes. Tanto Skinner, quanto Pocock atentam-se para os usos da linguagem e para o seu valor referencial, o qual seria verificável através da relação entre texto e contexto. Porém, as semelhanças entre suas abordagens terminam por aqui.

Enquanto Skinner problematiza os percursos metodológicos da história das ideias, as quais, na verdade, seriam enunciados, o que significa que elas se reportam a um contexto específico e comportam as intenções de seu autor - aqui, é notável a "recuperação" do autor na análise de um texto -, Pocock, por sua vez, interpreta os discursos como "atos de fala", frisando os aspectos performáticos da linguagem (SKINNER, 1969: 3 - 53). A história das linguagens políticas de Pocock é tributária da linguística saussuriana, que inaugura uma nova visão acerca das relações entre língua e realidade. Mais do que uma mera expressão da realidade, a língua a constitui. Saussure também rompeu com uma concepção engessada de "língua", propondo três maneiras de classificá-la: a langage, que corresponde a um conjunto de signos; a langue, que seria a 
langage apropriada, modificada e compartilhada por uma comunidade, servindo assim à comunicação; e, por fim, a parole, referente à utilização concreta da langue em um contexto específico. Sobretudo as duas últimas, langue e parole, relacionam-se de forma contínua e complexa entre si, ou seja, sincrônica e diacronicamente, conforme Pocock nos esclarece:

As linguagens têm como atributo a continuidade, tanto quanto a transformação. Mesmo quando modificadas pelo uso em contextos específicos, elas sobrevivem aos contextos nos quais foram modificadas e impõem sobre os atores dos contextos subsequentes as restrições para as quais a inovação e a modificação serão necessárias, porém imprevisíveis, respostas (POCOCK, 2003: 30)

Se a perspectiva de Skinner mostra-se mais centrada sobre o autor e suas intenções, a de Pocock enfoca o contexto através da perquirição das linguagens políticas que circulam por diferentes círculos e que sofrem novas reconfigurações conforme as experiências dos sujeitos. Seguramente, o método de Pocock impõe certos limites ao trabalho historiográfico, como a natureza da fonte documental, que deve ser um registro escrito. Por outro lado, trata-se de um método desafiador, uma vez que cabe ao historiador o papel de recuperar toda uma trama linguística e de aprender as linguagens de outros sujeitos para repensar seus pensamentos.

Partindo do pressuposto de que a história da ciência ocupa o terreno da história política, o arcabouço teórico-metodológico das histórias das ideias e das linguagens políticas contribui com o nosso objetivo de explorar a esfera científica, e, mais especificamente, a esfera da ciência médica, para além daquilo que ela nos aparenta ser: autônoma e neutro. A "gramática" empregada pelos cientistas das Luzes certamente visava garantir a legitimidade do autor, pois, caso contrário, ele não teria leitores ou adeptos de sua teoria científica. E como se legitimar perante o público leitor? As estratégias eram as mais variadas: explicitava-se a experiência, o fato de se ter visto com os próprios olhos; citavam-se grandes eruditos e cientistas, de diferentes nacionalidades; destacava-se a filiação a academias e sociedades científicas; explicitava-se a cristandade e a fé em Deus; e, por último, justificava-se a importância e utilidade pública de suas obras. 
Certamente, todos esses artifícios, principalmente o último, favoreceram a aproximação entre poder político e ciência, a qual passou a ser visto por monarcas de diversos países europeus segundo uma ótica pragmática. Nas palavras de Robert Fox, as monarquias que incentivaram a atividade científica o fizeram por “(...)a belief in the value of scientific knowledge (...) whose promotion would lend luster to any regime seeking to parade its adjustment, however cautious, to the beneficent forces of enlightenment and modernity." (PORTER, 2003: 107) . Uma forma deveras recorrente de promoção do saber e do conhecimento se deu através da fundação de sociedades e academias reais.

Entretanto, faz-se necessário atentar para o fato de que, malgrado espaços de sociabilidade científica, tais instituições estavam sob tutela do Estado e deveriam assim seguir uma série de normas e prescrições. De acordo com Franco Venturi, as dinâmicas das Luzes sustentaram-se na tensão entre a prática política e os ideais de progresso e bem-estar humano, os quais, se por um lado fomentaram o estabelecimento de reformas, por outro, também foram modificados segundo os limites destas. O Absolutismo ilustrado foi bastante representativo desta relação recíproca, já que se buscou, neste tipo de regime, um equilíbrio entre inovação e a tradição absolutista (VENTURI, 2003).

Além de Espanha, Prússia, Rússia e Áustria, um claro exemplo de regime absolutista ilustrado encontra-se no Portugal do Marquês de Pombal, secretário de Estado do reino de D. José I entre os anos de 1750 a 1777. Durante o período pombalino, estabeleceram-se reformas destinadas à secularização do tribunal da Inquisição e do ensino, destacando-se a reforma da Universidade de Coimbra, em 1772, que, além de promover uma renovação do ensino médico - conforme já apontamos acima -, consolidou o controle da educação pelo Estado e forneceu contingente humano para cargos burocráticos e administrativos.

Além da educação, também se deve considerar as mudanças concernentes à "gestão da vida", sobretudo após o terremoto de Lisboa, em 1755. Face às grandes perdas materiais e humanas, Pombal buscou não somente reconstruir a cidade de Lisboa, mas também implementar políticas de saúde pública. Dentre tais medidas, acreditamos que a criação da Intendência Geral da Polícia foi bastante representativa de uma articulação entre poder político e ciência médica, uma vez a salvaguarda da saúde pública promoveria o fortalecimento do poderio da monarquia portuguesa através do aumento da população. Esta última, considerada “(...) um dos fios condutores do mercantilismo - o número de homens faz a riqueza do Estado -, com as doutrinas 
fisiocráticas, então em voga, transforma-se numa das preocupações fundamentais do Estado" (SOUSA, 1995: 42).

Michel Foucault interpreta o surgimento das instituições policiais como uma consequência da modificação na relação entre Estado e população durante o século XVIII. Ao emergir como um "fenômeno natural", a população se torna uma unidade descritível, mensurável e governável, o que provocou uma redefinição do poder, que, se outrora remetia ao governo dos territórios, a partir de então passa a se referir ao "governo dos homens". Governar os homens significaria, de certa maneira, decifrar e conservar as forças constitutivas do Estado, e, neste sentido, os textos sobre polícia representam todo um esforço de teorização destas novas funções do Estado (FOUCAULT; SENELLART, 2008).

Igualmente, em Portugal, a ideia de polícia denotava manutenção da boa ordem. Todavia, seu significado tornou-se mais amplo na segunda metade do século XVIII, passando a incluir outros elementos relacionados à administração interna e ao bem comum e, aproximando-se assim da "ciência de polícia" ensinada nas Universidades de língua alemã. Para Alexandre Cunha, autor do artigo "Cameralism and Police science in Portugal", a ciência de polícia foi uma condição salutar ao estabelecimento do Absolutismo Esclarecido em Portugal, afinal, a noção mais alargada de polícia era bastante compatível com este tipo modelo político, pois reforçava o poder e as riquezas do Estado através de políticas que visavam o bem comum e a felicidade (CUNHA, 2010).

Criada por Pombal em 25 de junho de 1760, a Intendência Geral da Polícia teve como primeiro intendente Inácio Ferreira Souto, homem de confiança do marquês. Em 28 de janeiro de 1780, Pina Manique tomou posse do cargo de intendente geral, ocupando-o até 1805. Finalmente, em 1822 a instituição foi abolida. A despeito de a Intendência Geral da Polícia ter se ocupado inicialmente da insegurança nas ruas lisbonenses, a partir da nomeação de Pina Manique, que assumiu sua função de maneira enérgica, suas responsabilidades foram ampliadas: saneamento urbano, abastecimento e qualidade dos alimentos, acompanhamento de surtos epidêmicos, auxílio aos doentes, qualificação dos agentes da saúde e o recolhimento das listas dos povos. Trata-se de um momento em que a condenação ao chamado "charlatanismo", tanto reiterada no discurso médico, passa a ser apoiada pela Coroa, e, mais do que isso, torna-se uma política pública, implicando punições e até mesmo degredo dos "intrusos da medicina e 
da Cirurgia", conforme o próprio Sanches designava curandeiros e empíricos (SANCHES, 2003a: 3).

Portanto, acreditamos que considerar a atividade médica para além do âmbito científico, concentrando-nos também nos aspectos retóricos e linguísticos, e, articulando-a ao âmbito político, podemos compreender de maneira mais aprofundada a atuação e o discurso de médicos no que tange à proposição de políticas de saúde pública na Europa das Luzes. Como muito bem assinalado por Mario Biagioli: “(...) o poder não se concebe como um fator limitado a suas formas mais materiais, nem como uma coisa externa ao processo de criação de conhecimento." (BIAGIOLI, 1993: 14). No Portugal da segunda metade do Setecentos, podemos notar um estreitamento nas relações entre medicina e poder, seja o poder da legitimidade de curar, que os médicos lograram para si, ou o poder político, afinal, a Coroa desempenhou um papel preponderante no processo de afirmação da autoridade médica.

Mas há algo a mais a se considerar nessa aproximação. Se antes a autoridade médica limitava-se à esfera privada, à assistência destinada exclusivamente ao corpo individual e ao controle do processo patológico, a partir de tal aproximação, a medicina passa a se ocupar do corpo social, a intervir em problemas de saúde pública e a possuir prerrogativas embasadas em medidas do Estado (FASSIN, 1996). Por conseguinte, mais do que uma mera aproximação, a relação entre o campo médico e o campo político torna-se simbiótica, promovendo a reconfiguração tanto de um campo, quanto de outro. A partir de tal relação, ao passo em que o campo político redefine o seu poder, destinado menos ao território e mais à gestão da vida da população, o campo médico tem garantida a legitimidade de seu saber, complementando-se assim o processo de circunscrição e oficialização da medicina acadêmica em relação à medicina popular.

\section{Fontes}

MOLIÈRE; HUCHER, Yves (org.) (1970). Le malade imaginaire. Paris: Librairie Larousse.

OLIVEIRA, Francisco Xavier de; RAMOS, Vitor (compil.) (1968). Cavaleiro de Oliveira: trechos escolhidos. Rio de Janeiro: Agir.

SANCHES, Antônio Nunes Ribeiro. (2003a [1757]). Tratado da Conservação da Saúde dos Povos. Covilhã: Universidade de Beira Interior. . (2003b [1763]) Apontamentos para estabelecer-se um Tribunal e Colégio de medicina.

(2003c. [1763]). Método para Aprender e Estudar a medicina. 


\section{Referências bibliográficas}

ABREU, Jean Luiz Neves (2007). Ilustração, experimentalismo e mecanicismo: aspectos das transformações do saber médico em Portugal no século XVIII. Topoi, v. 8, n 15 , jul.-dez, pp. 80-104.

ABREU, Laurinda (2014). O poder e os pobres: dinâmicas políticas e sociais da pobreza e da assistência em Portugal (séculos XVI - XVIII). Lisboa: Gradiva.

BIAGIOLI, Mario (1993). Galileo courtier: the practice of science in the culture of absolutism. Chicago, IL: Univ. of Chicago.

CRESPO, Jorge (1990). A história do corpo. Rio de Janeiro; Lisboa: Bertrand Brasil: DIFEL.

CUNHA, Alexandre (2010). Police Science and Cameralism in Portuguese Enlightened Reformism: economic ideas and the administration of the state during the second half of the 18th century. E-journal of Portuguese History, vol. 8, n 1, pp. 36-47.

DULAC, Georges (2002). Science et politique: les réseaux du Dr António Ribeiro Sanches (1699-1783). Cahiers du monde russe, v. 43, nº. 2, pp. 251-274.

FASSIN, Didier (1996). L'espace politique de la santé: essai de genealogie. Paris: Presses Universitaires de France.

FLECK, Ludwik (2005[1935]). Genèse et développement d'un fait scientifique. Paris: Les Belles Lettres.

FOUCAULT, Michel; SENELLART, Michel (ed.) (2008). Segurança, território, população: curso dado no Collège de France (1977-1978). São Paulo, SP: Martins Fontes.

(1998) . O nascimento da clínica. Rio de Janeiro, RJ: Forense Universitária.;

FOX, Robert. Science and government. In: PORTER, Roy (org.) (2003). The Cambridge History of Science: Volume 4 Eighteenth Century. Cambridge University Press, pp. 107-128.

GRMEK, Mirko (org) (1995). Histoire de la pensée médicale en Occident: de la Renaissance aux Lumières. Paris: Seuil.

HARLAN, David. "A história intelectual e o retorno da literatura", In: RAGO, Luzia Margareth; GIMENES, Renato Aloizio de Oliveira (org.) (2000). Narrar o passado, repensar a história. Campinas, SP: UNICAMP/IFCH, pp. 13-60.

KANT, Immanuel (1974[1784]). Resposta à pergunta: Que é Esclarecimento?. In: Textos Seletos. Petrópolis, RJ: Vozes, pp. 100-117.

KUHN, Thomas S (2009[1962]). A estrutura das revoluções científicas. São Paulo, SP: Perspectiva.

LEBRUN, François (1995). Se soigner autrefois: médecins, saints et sorciers aux XVIIe et XVIIIe siècles. Paris: Seuil.

LINDEMANN, Mary (2002). Medicina e sociedade no início da Europa moderna. Lisboa: Replicação.

MARQUES, Vera Regina Beltrão (2003). Conselhos ao povo: os manuais de medicina doméstica no Setecentos. ANPUH - XXII Simpósio Nacional de História, João Pessoa. Disponível em: < http://anais.anpuh.org/? $\mathrm{p=16544}>$ Acesso em: 28 mar.2016.

MAXWELL, Kenneth (1997). Marquês de Pombal: paradoxo do iluminismo. 2. ed. Rio de Janeiro, RJ: Paz e Terra.

PIMENTA, Tânia (1997). Artes de curar: um estudo a partir dos documentos da Fisicatura-mor no Brasil do começo do século XIX. Dissertação (mestrado em História) - Universidade Estadual de Campinas, Instituto de Filosofia e Ciencias 
Humanas, Campinas, SP. Disponível em: http://libdigi.unicamp.br/document/?code $=000118425$. Acesso em: 02 set.2015.

PITA, João Rui (2000). Medicina, Cirurgia e Arte farmacêutica na reforma pombalina da Universidade de Coimbra, In: ARAÚJO, Ana Cristina (org.) O Marquês de Pombal e a universidade. Coimbra: Impr. da Universidade, pp. 129-162.

POCOCK, J. G. A (2003). Linguagens do ideário político. São Paulo, SP: EDUSP.

ROSEN, George (1994). Uma história da saúde pública. São Paulo, SP; Rio de Janeiro, RJ: Hucitec: Editora da UNESP: Associação Brasileira de Pós-Graduação em Saúde Coletiva.

SARAIVA, Antonio José (1994). Inquisição e cristãos-novos. 6. ed. Lisboa: Estampa.

SHAPIN, Steven; SCHAFFER, Simon (1985). Leviathan and the air-pump: Hobbes, Boyle, and the experimental life. Princeton: Princeton Univ. Press.

SKINNER, Quentin (1969). Meaning and Understanding in the History of Ideas. History and theory, vol. 8, $\mathrm{n}^{\circ}$ 1, pp. 3-53.

SOUSA, Fernando de (1995). A população portuguesa em finais do século XVIII. População e Sociedade. Porto: CEPFAM, nº 1, pp. 41-55.

VENTURI, Franco (2003). Utopia e reforma no Iluminismo. Bauru, SP: EDUSC.

WALKER, Timothy Dale (2005). Doctors, folk medicine and the Inquisition: the repression of magical healing in Portugal during the Enlightenment. Leiden; Boston: Brill.

Artigo recebido em 30 de março de 2016.

Aprovado em 03 de maio de 2016.

DOI: 10.12957/intellectus.2016.22262 